\title{
The Importance of SD Goals Indicators 7, 8, 9 and 12 in the Industry Development by Using Multi Criteria and Decision Making Method
}

\author{
Fisnik Osmani, Atanas Kochov*, Betim Shabani, Mirjeta llazi
}

\begin{abstract}
Sustainable Development and Decision Making are just two of the many processes that affect the industry sector. SDG7, SDG8, SDG9 and SDG 12 as four goals of sustainable development show the indicators we have to deal with, given that the energy, industry, economy and production are closely connected. This research focuses on promoting sustainable development in the industry, by testing very important indicators using the MCDM method. Our analysis was carried out with the help of a multi-criteria decision-making method - the Hierarchical Analytical Process. Through this method, we have identified specific areas that need improvement, the importance of the indicators separately, ranking so by their importance and impact in the industry, economy and production.
\end{abstract}

Keywords: decision-making; energy; industry; MCDM; sustainable development

\section{INTRODUCTION}

Energy is a vital need for a functioning society. Add here the economic development, the need for foreign investment, consumption, and production - all members of the system that have a significant impact on sustainable development in the industry.

Developing countries are trying to improve their standard of living through industrialization. In this regard, it is important to analyze the indicators that have an impact on improving the overall situation, and this can be done based on the Sustainable Development Goals (SDG 17). This, in fact, is the focus of this paper - to figure the relevance of each factor based on scientific methods of decision-making and on expert opinion (based on interviews with twenty experts). Most countries in the Western Balkans region face similar issues and thus a thorough analysis can bring a solution that can serve and be applied to all [1].

Since the fact that the process of monitoring regional industrial sustainability could be rather difficult, due to the many stakeholders and objectives, empirical literature has proposed a variety of indicators for the assessment of the industrial sustainability, including social, economic, and environmental determinants [2].

One of the most important indicators, especially when talking about sustainable development, is the investment indicator, which is of great importance in our analysis. To deal with decision making for different kinds of problems and try to solve them is difficult even more if there is a need to obtain information from a group of decision-makers [3]. Therefore, especially in the recent years, the need to improve sustainability in industrial activities has increased the interest of policy-makers and industrial decision-makers (IDMs). Even if firms started to include sustainability at a strategic level, current modes of production cannot be considered sustainable, and significant changes are needed at a technological, managerial, organizational, and behavioral level [4].
One of the most important goals is the economic development in the industrial sector, particularly in developing countries [5] where it should be maintained and needs to be taken into consideration, as required by the nature of sustainable development.

Given the factual situation, we have analyzed the possibility of applying the indicators according to SDG7SDG8-SDG9 and SDG12 in theoretical terms, thus achieving results/solutions to guarantee the participation of clean energy factors, innovation and infrastructure, as more important elements for sustainable development.

\section{CONSIDERABLE INDICATORS IN THE DECISION- MAKING ANALYSIS}

SDG's, especially in the industry, are closely related to Clean and Sustainable Energy, Investment, Work and Economy Growth, Consumption and Production (Fig. 1). Based only on the broader meaning of these two purposes by the UN, we conclude that sustainable development in the industry has to do with the idea that all requirements that we have towards the environment can be met without harming the opportunities of others but by improving the situation for future generations.

We have come to a situation where we need to understand the importance of incorporating indicators from SDG7- SDG8-SDG9 and SDG12 where vital/key issues for sustainable development in the industry are touched upon. Therefore, in order to define key indicators for sustainable development in the industry (Fig. 2), we have considered indicators as in Tab. 1. 


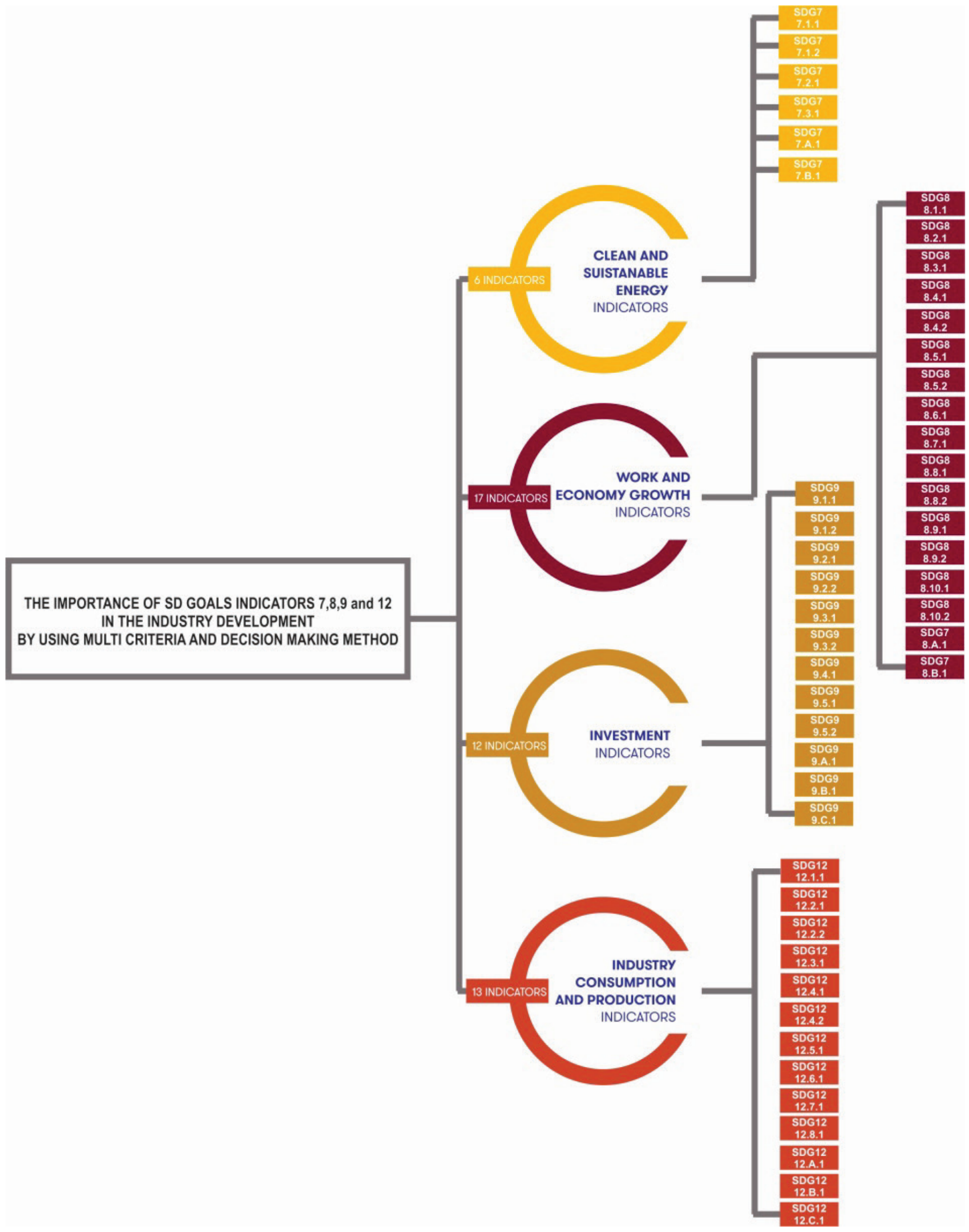

Figure 1 Sustainable Development Goals SDG7 / SDG8 / SDG9 / SDG12 [6] 


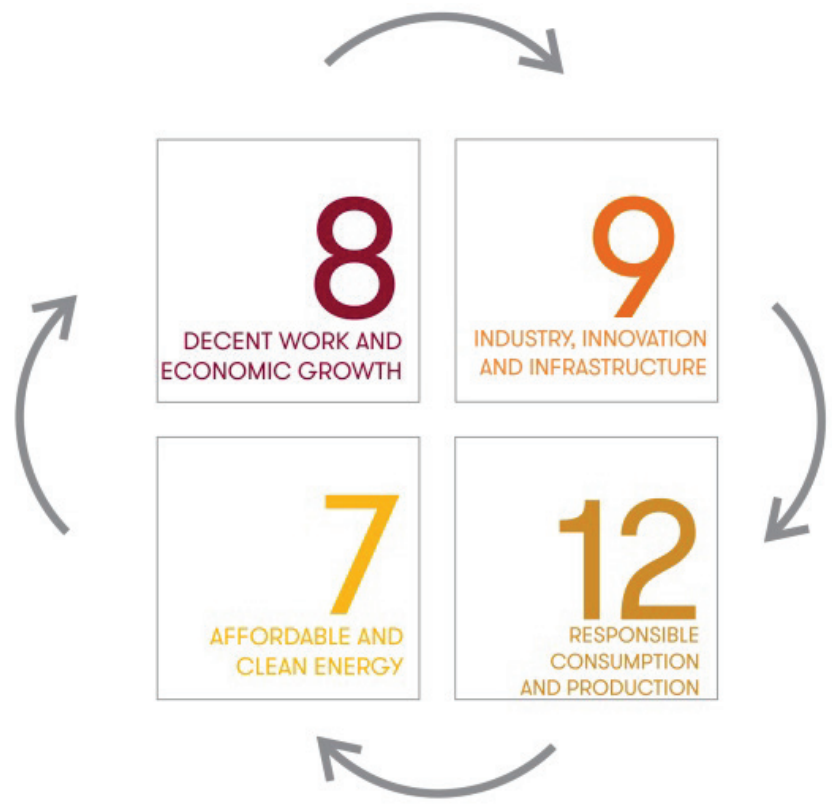

Figure 2 Sustainable Development Goals SDG7 / SDG8 / SDG9 / SDG12 [6]

Table 1 Analyzed indicators of all levels of the hierarchy of the problem
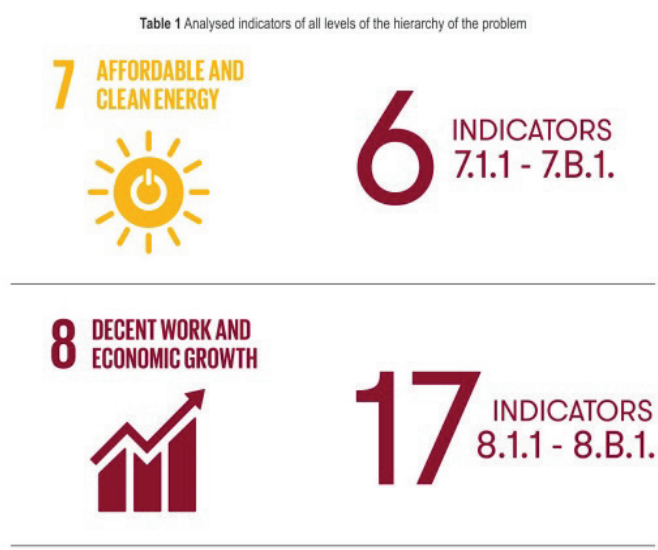

INDUSTRY,INNOVATION

ANDINFRASTRUCTURE
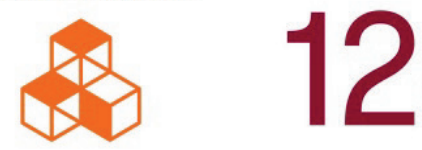

INDICATORS 9.1.1 - 9.C.1.

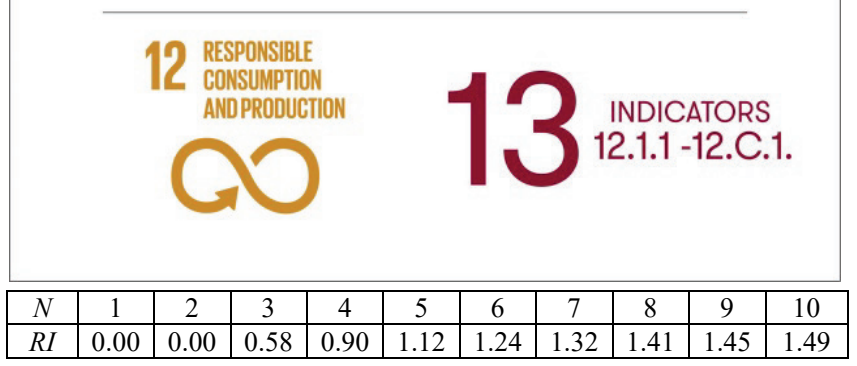

\section{DECISION-MAKING PROCESS APPLICATION OF AHP METHOD}

The AHP method developed by Thomas L. Saaty [7] stands as one of the most commonly used methods of multicriteria analysis. This method sees the decision-making process to be a hierarchical process with multiple levels.

In decision making, especially when we talk about sustainable development in the industry, it is very important which method we decide to use to achieve optimal solutions. So why have we decided to use the Analytic Hierarchy process in particular?

The AHP works as a hierarchy, breaking down the decision top to bottom. The goal is at the top level, the criteria and sub-criteria are in middle levels, and the alternatives are at the bottom layer of the hierarchy.

Input of experts and decision-makers is considered as pair-wise comparison and the best alternative can be selected according to the highest rank between alternatives. It is noticed that AHP is the most used methodology of all the MCDM methods. This can be credited to its simple structure and the ability of an analyst to negotiate results until consistency is achieved, offering near consensus on judgment. [8]

Table 2 Theoretical basis of MCDM - AHP Method $[11,12,1]$

The characteristics of matrix $\boldsymbol{A}$.

$a_{i j}=1 ; a_{i j}=1 / a_{i j}$ for $i, j=1, \ldots, n ; \operatorname{det} \boldsymbol{A} \neq 0$

Determining the weights can be solved same as solving a matrix equation with matrix columns $w$ solution for eigenvalues $\lambda$ different from o i.e.

$\boldsymbol{A} \cdot w=\lambda \cdot w$, or $\left[\begin{array}{cccc}a_{11} & a_{12} & \cdots & a_{1 n} \\ a_{21} & a_{22} & \cdots & a_{2 n} \\ \cdots & \cdots & \cdots & \cdots \\ a_{n 1} & a_{n 2} & \cdots & a_{n n}\end{array}\right] \cdot\left[\begin{array}{c}w_{1} \\ w_{2} \\ \cdots \\ w_{n}\end{array}\right]=\left[\begin{array}{c}\lambda_{1} w_{1} \\ \lambda_{2} w_{2} \\ \cdots \\ \lambda_{n} w_{n}\end{array}\right]$

Priority vectors (w) from the pair-wise comparison matrix $\boldsymbol{A}$ by solving an eigenvalue problem whit the relation.

$\boldsymbol{A} \cdot w=\lambda_{\max } \cdot w$

Where $\lambda_{\max }$ is the maximum eigenvalue of $\boldsymbol{A}$

Assessment, or to calculate index of consistency.

$\mathrm{CI}=\left(\lambda_{\max }-n\right) /(n-1)$

Based on this index we determine the index of inconsistency

$C R=C I / R I$

Where: $R I$ (Random Index)

The value of $C R \leq 0.10$ shows that the estimates for $a$ and $j$ are consistent. In case they are not, the evaluation should be repeated.

\begin{tabular}{|c|c|c|c|c|c|c|c|c|c|c|}
\hline$N$ & 1 & 2 & 3 & 4 & 5 & 6 & 7 & 8 & 9 & 10 \\
\hline$R I$ & 0.00 & 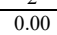 & 0.58 & 0.90 & 1.12 & 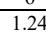 & $\frac{1}{1.32}$ & 1.41 & 1.45 & 1.49 \\
\hline \multicolumn{11}{|c|}{ Saaty's 9-point scale of pair-wise comparison. } \\
\hline \multicolumn{3}{|c|}{ Scale } & \multicolumn{8}{|c|}{ Compare factor of $i$ and $j$} \\
\hline \multicolumn{3}{|c|}{1} & \multicolumn{8}{|c|}{ Equally important } \\
\hline \multicolumn{3}{|c|}{3} & \multicolumn{8}{|c|}{ Weakly important } \\
\hline \multicolumn{3}{|c|}{5} & \multicolumn{8}{|c|}{ Strongly important } \\
\hline \multirow{2}{*}{\multicolumn{3}{|c|}{$\begin{array}{l}7 \\
9\end{array}$}} & \multicolumn{8}{|c|}{ Very strongly important } \\
\hline & & & \multirow{2}{*}{\multicolumn{8}{|c|}{$\begin{array}{l}\text { Extremely important } \\
\text { Intermediate value between adjacent scales }\end{array}$}} \\
\hline \multicolumn{3}{|c|}{$2,4,6,8$} & & & & & & & & \\
\hline
\end{tabular}

Analytic Hierarchy Process (AHP) has many advantages including its adaptive application; it is scalable; it has a hierarchy structure that can easily adjust to fit many sized problems; it is not data intensive, etc. [9] Inside MCDM, 
AHP is one of the most efficient methods for dealing with different problems. [10]

The procedure follows numerous steps, including: assigning a relative assessment in pairs with attributes of a hierarchical level, for given attributes of the first and higher hierarchical level, and then repeating the process for all levels of the hierarchy. [1] Naturally, the application of the theoretical basis is required, which is given in Tab. 2.

\section{HIERARCHY OF THE PROBLEM AND ALTERNATIVES BASED ON AHP METHOD}

The analysis of indicators is examined in three main areas/main indicators. There are 48 indicators from the second level of the hierarchy that will be compared with the four alternatives (Investment in Education, Investment in the Energy Sector, Investment by Foreign Investment, Investment in the Infrastructure and Innovation). The whole analysis is done based on the diagram below (Figure 3). After analyzing the data and processing with Expert Choice
Software, we have obtained the results. The results structure a hierarchy that will be a good basis for decision-making and policy-making for the impact of sustainable development in the industry. Diagrams with the results obtained after processing all the data will be presented in the following chapters.

The results (Tab. 3) show that Alternative 1 - Investment in Education has an advantage over the other three alternatives. From this point of view, sustainable development suggests the scale towards Alternative 1 with a slight advantage over other alternatives. However, Alternatives 2 and 3, based on our analysis, are very close and should not be neglected completely as they represent the corresponding alternatives derived from the model. Based on these results, we note that Sustainable Development Goals are closely related to Investment in Education, Investment by Foreign Investors, Investment in Energy, and Investment in Infrastructure and Innovation.

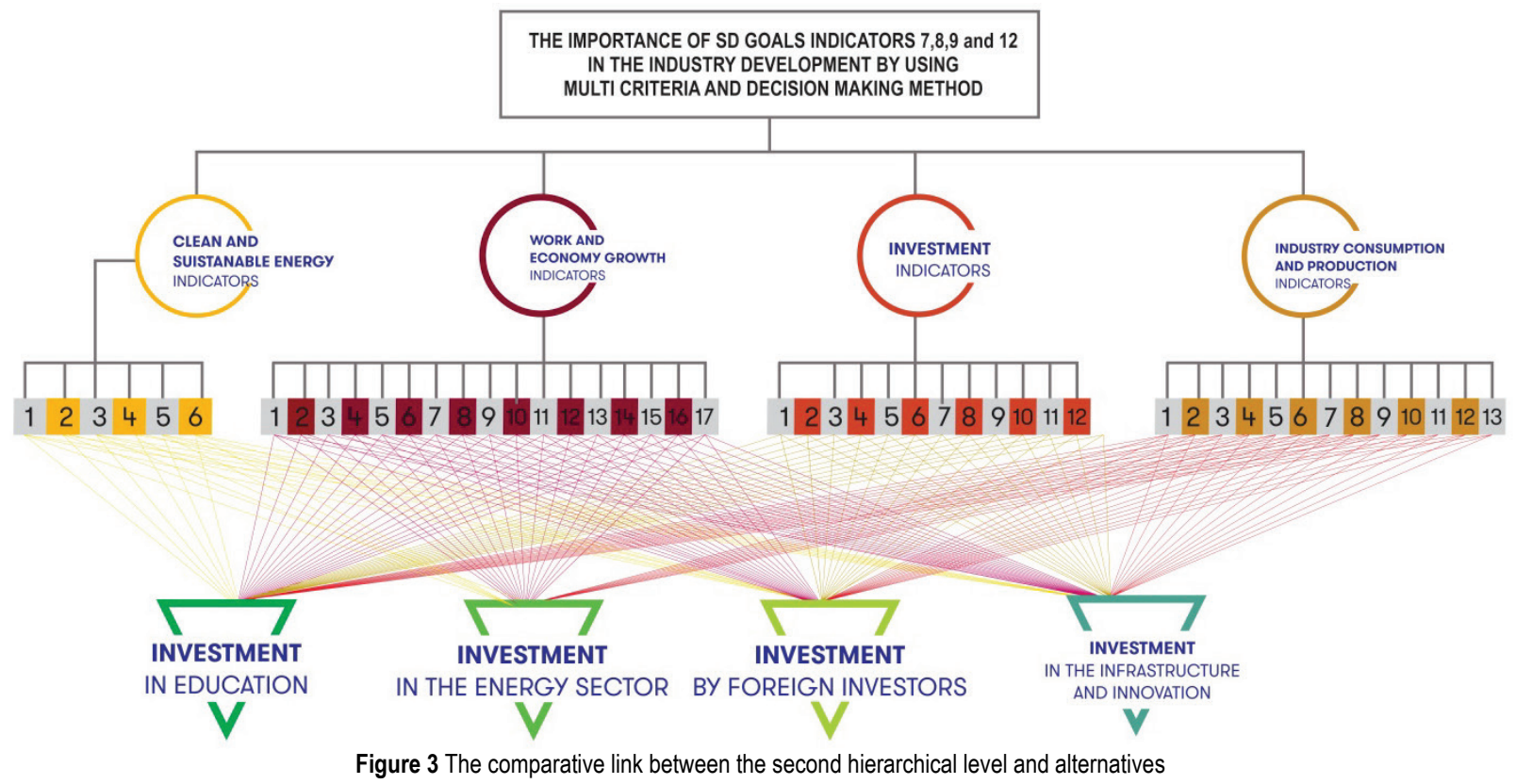

Table 3 Ranking of Alternatives

\begin{tabular}{|l|l|c|c|}
\hline Alternative 1 & Investment in Education & $\mathbf{0 . 3 8 2}$ & $\mathbf{1}$ \\
\hline Alternative 2 & Investment in the Energy Sector & 0.208 & 3 \\
\hline Alternative 3 & Investment by Foreign Investors & 0.266 & 2 \\
\hline Alternative 4 & $\begin{array}{l}\text { Investment in the Infrastructure and } \\
\text { Innovation }\end{array}$ & 0.143 & 4 \\
\hline
\end{tabular}

The successful implementation of the AHP method requires that experts maintain the dominant role in ranking the indicators and alternatives. They contributed through the interviews they provided based on Saaty's rules. The university professors' opinions are crucial for our analysis, as universities are the main actors in teaching, research, and support for the implementation of clean production activities [1]. Since we are dealing with theoretical analysis, we have focused mainly on getting the opinion of university professors. However, the participants in our analysis were not just members of the academic community, but also decisionmakers in relevant institutions such as mayors, department directors, board directors, etc.

The complete calculations of the analysis for all indicators - part of the model for three levels of the hierarchy - were made by applying Expert Choice Software. Through it, it is possible to achieve results in all the steps followed by the AHP methodology through Expert Choice. Here are the steps: Pairwise Comparisons, Judgment Scales, Priorities Derivation, Consistency, Aggregation - which are displayed at the end through sensitivity analysis (performance sensitivity, dynamic sensitivity, gradient sensitivity, head to head sensitivity) as a final step (Fig. 4). 

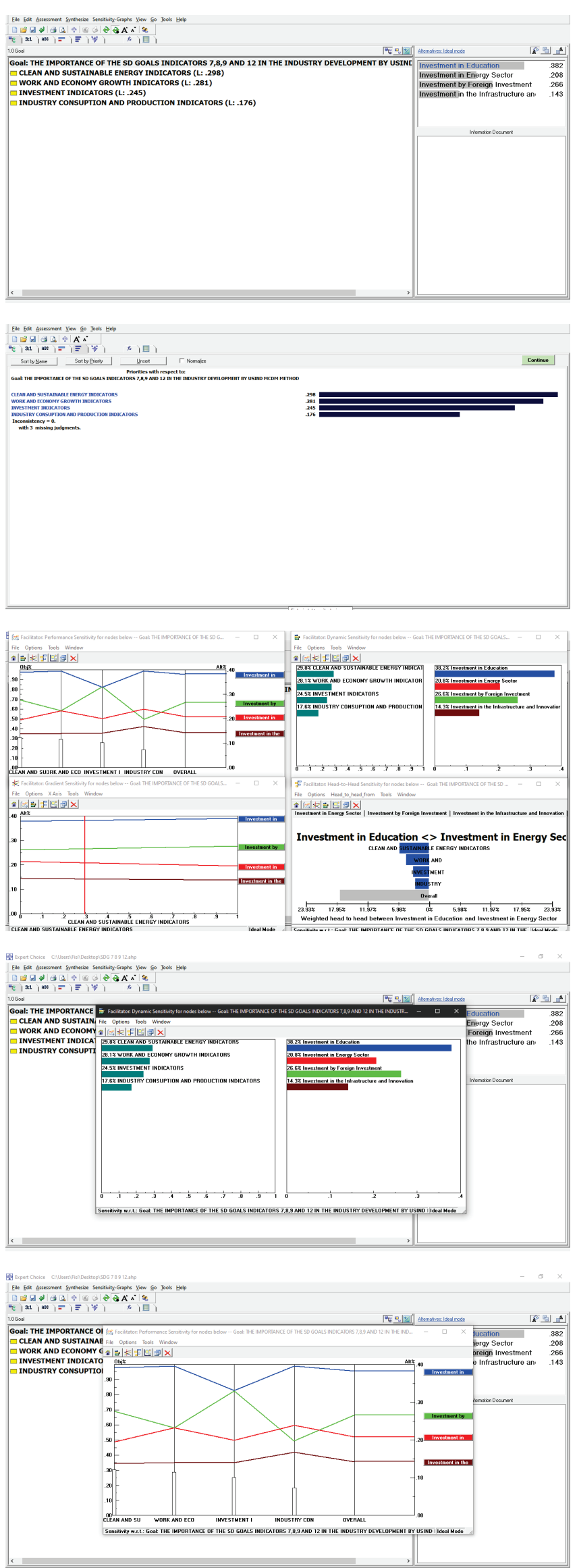
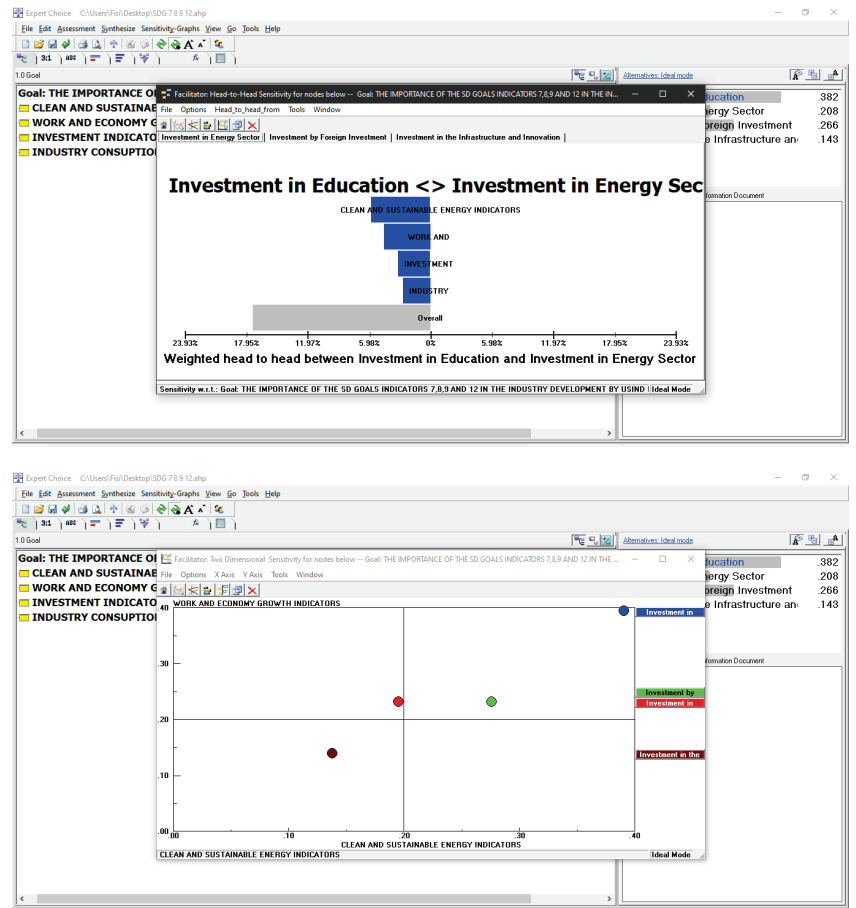

Figure 4 The program interface through which the calculations for the Technicalenergetic Indicators, Environmental and Social Indicators, Economic-Investment Indicators have been made

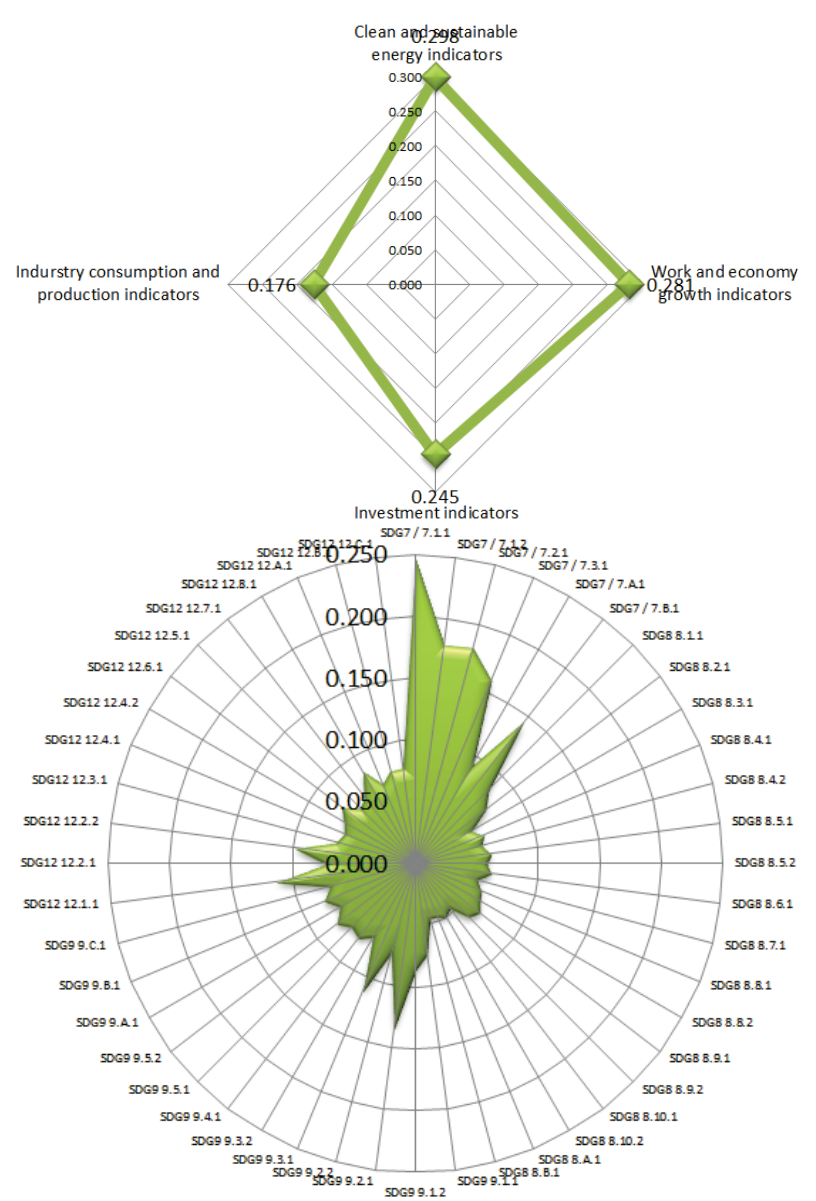

Figure 5 Graphic presentation of the final results for the Clean and Sustainable Energy Indicators, Work and Economy Growth Indicators, Investment Indicators, Industry Consumption and Production Indicators distributed in the three hierarchical levels of the model. 
The summary of the results we obtained through the application of Expert Choice, are presented in summary form in Fig. 5. Here the final values of the alternatives tested in the analysis are presented with the values of all indicators analyzed in the whole model.

\section{CONCLUSIONS AND RECOMMENDATIONS}

Using the AHP Method, we have set the indicators, identified their weight, defined the hierarchy of the problem, and offered alternatives. This does not imply that we are talking about a method through which we can solve real problems that mankind faces nowadays. Nevertheless, we have managed to define our future goal, use, and application of other methods in the field of decision-making and multicriteria policy for Developing Countries (Western Balkans region) in projects that enable sustainable development.

The results acquired can give a fair picture of the appropriate steps to be taken to intervene and change the situation, based on the indicators that we have taken into account. According to the Clean and Sustainable Energy Indicators (0.298) resulted in Indicator 7.1.1 Proportion of population with access to electricity worth (0.246).

In the second part of the Work and Economy Growth Indicators we have reached the highest value in the annual growth rate of real GDP per capita (0.083).

Investment Indicators $(0.245)$ achieved its highest value through the Proportion of rural population indicator who live within $2 \mathrm{~km}$ of an all-season road (0.135).

The last indicators, Industry Consumption and Production Indicators $(0.176)$, reach the maximum value in the indicator Number of countries with sustainable consumption and production (SCP) or SCP mainstreamed as a priority or target in national policies with value $(0.114)$.

The results of the analysis will be used as a base for developing countries (Western Balkans) in the logic of identifying, analyzing, and taking appropriate steps in the right direction. The research has raised many new questions and paves the way for potential new research in this field of study. The Republic of Kosovo in particular and the region in general, need to address these issues in the future in order to define more indicators that have an impact on the sustainable development of their respective territories. The span of the applicability of this particular model can easily expand to include other countries in the region. With some alterations, the model can reach a broader acceptance in the region. As for the term "wider", it is comprised of institutional inclusion of the proven scientific methods and techniques in decision making, as well as applying existing models and studies from one country into another country in the region of Western Balkans.

Moreover, the model (besides contributing towards the identification of problems) will offer these solutions:

- To identify, define, and plan the most crucial criteria in the hierarchy of the sustainable industry based on the SDG's;

- To alter/modify models which will be established carefully for each different case specifically;
- To establish the model to solve similar problems, in accordance with the recommendations for further work, by the use of the analytic hierarchy process;

- Our analysis can also be utilized for similar cases in the field of decision making concerning sustainable industry.

\section{Notice}

The paper was presented at MOTSP 2020 - International Conference Management of Technology - Step to Sustainable Production, which took place from $30^{\text {th }}$ September $-2^{\text {nd }}$ October 2020 in Bol, island Brač (Croatia). The paper is not and will not be published anywhere else.

\section{REFERENCES}

[1] Osmani, F. \& Kochov, A. (2018). Definition of indicators for decision-making to contribute to sustainable development through Cleaner Production and Resource Efficiency by using the AHP method. Lietuvos mokslu akademija, Energetika, 64(3), 149-160. https://doi.org/10.6001/energetika.v64i3.3808

[2] Condona, E., Goldenb, B., \& Wasilc, E. (2003). Visualizing group decisions in the analytic hierarchy process. Computers \& Operations Research, 30, 1435-1445. https://doi.org/10.1016/S0305-0548(02)00185-5

[3] Neri, A., Cagno, E., Di Sebastiano, G., \& Trianni, A. (2018). Industrial sustainability: Modelling drivers and mechanisms with Barriers. Journal of Cleaner Production, 194, 452-472. https://doi.org/10.1016/j.jclepro.2018.05.140

[4] Wang, C., Wang, L., \& Dai, S. (2018). An indicator approach to industrial sustainability assessment: The case of China's Capital Economic Circle. Journal of Cleaner Production, 194, 473-482. https://doi.org/10.1016/j.jclepro.2018.05.125

[5] Kates, R. W., Parris, T. M., \& Leiserowitz, A. A. (2005). Environment: Science and Policy for Sustainable Development what is Sustainable Development? Goals, Indicators, Values, and Practice, 47(3), 8-12. https://doi.org/10.1080/00139157.2005.10524444

[6] Saaty, T. L. (1980). Multicriteria Decision Making: The Analytic Hierarchy Process. McGraw-Hill, New York. https://doi.org/10.21236/ADA214804

[7] Saaty T. L. \& Gholamnezhad A. H. (1982). High-Level Nuclear Waste Management: Analysis of Options. Environmental Planning, 9, 181-196. https://doi.org/10.1068/b090181

[8] Rimal, T. A. \& Tugrul, D. (2013). Multi-Criteria Applications in Renewable Energy Analysis, a Literature Review. Research and Technology Management in the Electricity Industry. Springer, VIII. p. 359.

[9] Velasquez, M. \& Hester, P. T. (2013). An Analysis of MultiCriteria Decision Making Methods. International Journal of Operations Research, 10(2), 56-66.

[10] Triantaphyllou, E., Shu, B., Nieto Sanchez, S., \& Ray, T. (1998). Multi-Criteria Decision Making: An Operations Research Approach. Encyclopaedia of Electrical and Electronics Engineering, (Webster, J. G. Ed.), John Wiley \& Sons, New York, NY, Vol. 15, 175-186.

[11] Miller, G. (1956). The magical number seven, plus or minus two: some limits on our capacity for processing information. The Psychological Review, 63(2), 81-97. https://doi.org/10.1037/h0043158 
[12] Saaty, T. L. (1994). How to make a decision - The Analytic Hierarchy Process. Interfaces, 19-43.

https://doi.org/10.1287/inte.24.6.19

\section{Authors' contacts:}

Prof. ass. dr. Fisnik Osmani

University of Mitrovica, Faculty of Mechanical Engineering and Computer,

Fabrika e Akumulatorëve, 40000 Mitrovica, Kosovo

fisnik.osmani@umib.net

\section{Prof. dr. sc. Atanas Kochov}

(Corresponding author)

University "St. Cyril and Methodius" Skopje,

Faculty of Mechanical Engineering,

Karpos II b.b. P. O. Box 464,

1000 Skopje, Republic of North Macedonia

atanas.kochov@mf.edu.mk

MSc. Betim Shabani, PhD Candidate

University "St. Cyril and Methodius" Skopje,

Faculty of Mechanical Engineering,

Karpos II b.b., 1000 Skopje, Republic of North Macedonia

MSc. Mirjeta llazi, PhD Candidate

University "St. Cyril and Methodius" Skopje,

Faculty of Mechanical Engineering,

Karpos II b.b., 1000 Skopje, Republic of North Macedonia 